\title{
Effect of Ulex europaeus L. extracts on polyphenol concentration in Capsicum annuum $\mathrm{L}$. and Lactuca sativa $\mathrm{L}$.
}

\author{
Ricardo Tighe-Neira ${ }^{1,4}$, Ramiro Díaz-Harris ${ }^{2}$, Gina Leonelli-Cantergiani ${ }^{1}$, Patricia Mejías- \\ Lagos $^{2}$, Carla Iglesias-González ${ }^{1}$ Claudio Inostroza-Blancheteau ${ }^{1,3^{*}}$
}

${ }^{1}$ Departamento de Ciencias Agropecuarias y Acuicolas, Facultad de Recursos Naturales, Universidad Católica de Temuco, Rudecindo Ortega 02950, Temuco, Chile. '2Departamento de Ciencias Biológicas y Químicas, Facultad de Recursos Naturales, Universidad Católica de Temuco, Rudecindo Ortega 02950, Temuco, Chile. ${ }^{3}$ Núcleo de Investigación en Producción Alimentaria, Facultad de Recursos Naturales, Universidad Católica de Temuco, Rudecindo Ortega 02950, Temuco, Chile. ${ }^{4}$ Programa de Doctorado en Ciencias Agropecuarias, Facultad de Recursos Naturales, Universidad Católica de Temuco, Rudecindo Ortega 02950, Temuco, Chile.*Corresponding author: claudio.inostroza@uct.cl

\begin{abstract}
In this work, the effect of aqueous and methanolic extracts from roots and shoots of Ulex europaeus $\mathrm{L}$. on the total polyphenol content of Capsicum annuum L. and Lactuca sativa L. grown in laboratory and greenhouse conditions was evaluated. Treatments consisted of $U$. europaeus L. extracts (20, 40, 80, 160 and $320 \mathrm{mg}$ $\mathrm{kg}^{-1}$ ) as well as caffeine and distilled water as controls, all of which were applied with a manual sprayer on seedlings of the aforementioned species. Total polyphenols were determined using the Folin-Ciocalteu method. Under control conditions, the polyphenol concentration in C. annuum was lower in laboratory than in greenhouse conditions $(P<0.05)$. Conversely, L. sativa had a higher polyphenol concentration in the laboratory than in the greenhouse $(P<0.05)$. Also, under laboratory conditions the polyphenol content rose with increasing extract doses in both species, but this tendency was not observed in the greenhouse. Finally, different doses of extracts of $U$. europaeus L. affect total polyphenol content in both species. This effect is clear under laboratory conditions, but not in greenhouse experiments. These findings open up the possibility of cultivating species with higher antioxidant contents using natural products.
\end{abstract}

Keywords: Ulex europaeus L., polyphenols, extract, caffeine, antioxidant, plant stress. 


\section{Introduction}

Vegetables are an important source of chemical diversity, useful in both agriculture and medicine (Kolewe et al., 2008). Part of this diversity is due to substances called secondary metabolites, which belong to three main groups: terpenes, phenolic compounds and nitrogenous compounds (Zhong, 2011; Ortiz de Elgueta-Culebras et al., 2017). These are produced as defence or protection mechanisms when adapting to the environment, and when facing stressful conditions, but are not essential for vital functions (Dixon and Paiva, 1995; Bourgaud et al., 2001). Medeiros et al. (2009) point out that substances such as the alkaloids in plant extracts can activate secondary metabolism, as they themselves constitute an abiotic stress and therefore induce the production of polyphenols (Koyama et al., 2012). The latter is reported as the concept of elicitation that is generated by an elicitor (Ramirez-Estrada et al., 2016). This is relevant as polyphenols compose a group of natural antioxidants that have the ability to neutralise free radicals and play an important role in modulating enzymatic detoxification, resulting in beneficial effects for human health (Costa et al., 2009; Andarwulan et al., 2012; García-Tirado et al., 2012; Martini et al., 2017; Tighe-Neira et al., 2017). In this sense, botanic extracts may be used to biostimulate secondary metabolism in other vegetables, as has been observed with extracts of marine algae as a stress-causing agent (Araujo et al., 2012; Tighe et al., 2014). Batish et al. (2008) found similar results using caffeine in doses of $2000 \mu \mathrm{M}$ on Phaseolus aureus Roxb. Similarly, U. europaeus, originating in Western Europe and considered an invasive weed (Matthei et al., 1995; Kaufman and Kaufman, 2013), is a species of interest, as phytochemical studies have shown it contains secondary metabolites such as flavonoids, tannins, polyphenols and quinolizidine alkaloids including anagrine, cytosine, N-methylcyto- sine, and lupanine (Hornoy et al., 2012). On the other hand, red hot chilli pepper (Capsicum annuиm) and lettuce (Lactuca sativa) are important horticultural species with great nutraceutical properties (Cheng et al., 2014; Korkutata and Kavas, 2015; Sayin and Arslan, 2015). These species are widely cultivated in greenhouse conditions, leading to constant production throughout the year (Batlang, 2008; Ioslovich, 2009). Therefore, based on the principle mentioned by Medeiros et al. (2009) and Koyama et al. (2012), we hypothesized that $U$. europaeus extracts could influence the secondary metabolism of species of agronomic interest, increasing their total polyphenol content. In this work, we have selected $C$. annuum $\mathrm{L}$. and $L$. sati$v a \mathrm{~L}$ as models to evaluate the effect of applying different doses of aqueous and methanolic extracts from $U$. europaeus L. on seedlings of the models species grown in laboratory and greenhouse conditions.

\section{Materials and Methods}

\subsection{Plant material and treatments}

The assays were conducted in the Plant Biotechnology Laboratory of the Departamento de Ciencias Agropecuarias y Acuícolas and in the Chemistry of Natural Products Laboratory of the School of Environmental Sciences, both at Universidad Católica de Temuco. Greenhouses were facilitated by Agroindustry Daube Ltda., Camino Botrolhue km 5.5, Temuco, La Araucanía Region, Chile. Furthermore, U. europaeus was obtained from the Pillanlelbún Experimental Centre, Departamento de Ciencias Biológicas y Químicas, Universidad Católica de Temuco, from which C. annuum (Cacho de Cabra) seeds, and L. sativa were also collected. After collection, U. europaeus was dried at room temperature, separated into above-ground 
(shoot) and below-ground (root) fractions, and ground to make the extracts. The extracts were obtained according to Alghazeer et al. (2012) with some modifications. Nonetheless, for specific, aqueous extracts we used the methodology described by Benayad et al. (2013). Thus, the extract was obtained by infusing 5 $\mathrm{g}$ of material in $100 \mathrm{~mL}$ of distilled water at $90^{\circ} \mathrm{C}$. On the other hand, the methanolic extracts were obtained by incubating $10 \mathrm{~g}$ of plant material in $40 \mathrm{~mL}$ of methanol, changing solvent every $48 \mathrm{~h}$ by a period of six days (Karthishwaran et al., 2010). All extracts were vacuum filtered with filter paper $\mathrm{N}^{\circ} 2$ and then clarified by centrifugation at $5000 \mathrm{rpm}$ for $10 \mathrm{~min}$. The resulting fractions were then standardised in their concentration (total dissolved solids) and stored in chilled, sterilised plastic bottles until use.

The $L$. sativa and $C$. annuum seeds were disinfected by constant agitation in a Captan solution $(0.5 \mathrm{~g}$ in $100 \mathrm{~mL}$ of distilled water) for $30 \mathrm{~min}$. Subsequently, they were washed with distilled water and dried. $C$. annuи seeds were immersed in distilled water for $15 \mathrm{~h}$ before being used. For laboratory assays, seeds of both species were placed in glass bottles $(215 \mathrm{~mL})$ with three circles of $\mathrm{N}^{\circ} 1$ filter paper inside. Fifty seeds of each species were deposited per bottle in a laminar flow bench (Arquimed, AHC - 5A1), and 1 $\mathrm{mL}$ solution applied per treatment (see Table 1). The bottles were sealed with plastic film and maintained at $21 \pm 2^{\circ} \mathrm{C}, 100 \mu \mathrm{mol} \mathrm{m} \mathrm{m}^{-2} \mathrm{~s}^{-1}$ and a photoperiod of $16 / 8 \mathrm{~h} \mathrm{light/darkness} \mathrm{in} \mathrm{a} \mathrm{growth} \mathrm{chamber} \mathrm{(Inema).}$ For greenhouse assays, a $250 \mathrm{~m}^{2}$ greenhouse with a polyethylene cover was used. In addition, on a desk $1.20 \mathrm{~m}$ high, the germination and development of the previously-disinfected seeds was carried out, using containers of expanded polystyrene $\left(1.25 \times 10^{-4} \mathrm{~m}^{3}\right)$ and a mixture of soil, compost and sand in a ratio of $1: 1: 1$, previously sterilised three times at $121^{\circ} \mathrm{C}$ for 30 $\min$ (HL-340 vertical autoclave). Three $\mathrm{mL}$ of each treatment (see Table 1) was applied to each seedling with a manual $500 \mathrm{~mL}$ sprayer, every seven days on four occasions, once the first true leaf had appeared. Five doses of each extract type (aqueous and methanolic) for shoot and root fraction of U. europaeus were used as treatments as described Tighe et al. (2016). Also, was considered distilled water as an absolute control, and caffeine p.a. as a positive control Table 1.

Table 1. Treatments used in laboratory and greenhouse assays.

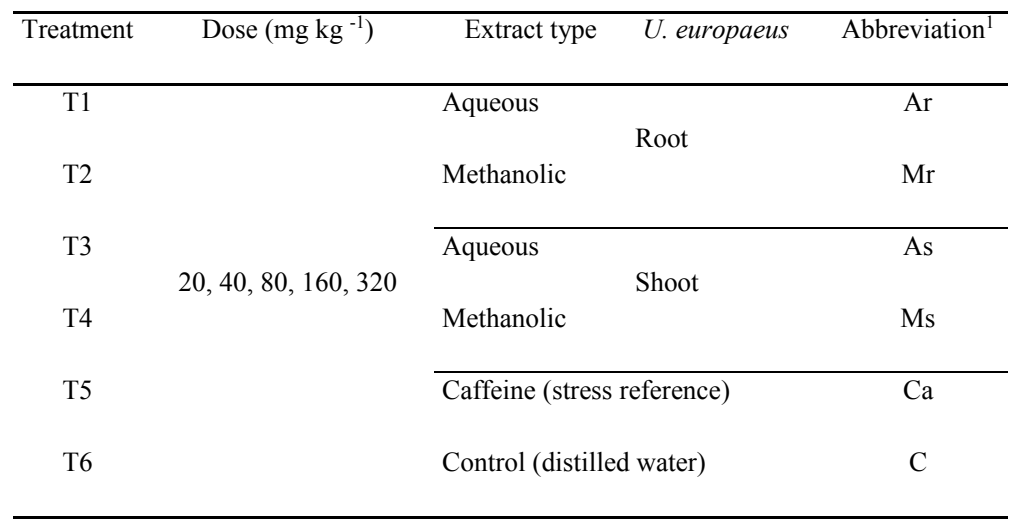

${ }^{1} \mathrm{Ar}=$ root aqueous, $\mathrm{Mr}=$ root methanolic, $\mathrm{As}=$ shoot aqueous, $\mathrm{Ms}=$ shoot methanolic, $\mathrm{Ca}=$ caffeine, $\mathrm{C}=$ control. 


\subsection{Phytochemical analysis}

A phytochemical analysis of the extracts was undertaken according to published methods (Pascual et al., 2002; Karthishwaran et al., 2010; Upadhyay et al., 2010). Briefly, alkaloids were determined using Dragendorff reagent in drop tests on dye plates, and by thin-layer chromatography on silica gel plates visualized under UV-365 nm lights. Flavonoids were determined by reaction with metallic $\mathrm{Mg}$ in an acid medium. The tannins were identified with $\mathrm{FeCl}_{3}$ solution at $10 \%$, and confirmed with gelatine and gelatine-salt solution. The presence of saponins was determined by the foam test and confirmed with vanillin-sulphuric acid reagent.

\subsection{Determination of total polyphenol concentration}

The total polyphenol concentration was performed according to the Folin-Ciocalteau method (Georgé et al., 2005). The reagents used were: acetone: water (7:3 $\mathrm{v} / \mathrm{v})$, sodium carbonate solution ( $\left.75 \mathrm{~g} \mathrm{~L}^{-1}\right)$, Folin solution (diluted in 10 parts of water) and gallic acid (5
- $25 \mathrm{mg} \mathrm{L}^{-1}$ ). A gallic acid curve was prepared as standard by determining the absorbance value in a spectrophotometer (Optizen) at $760 \mathrm{~nm}$. The results were expressed in mg Equivalent of Gallic Acid (EGA) per $100 \mathrm{~g}$ of dry material.

\subsection{Experimental design and statistical analysis}

The experimental units were placed in a block design completely at random, for both laboratory and greenhouse assays. For the separation of means, an ANOVA test, a Tukey multiple comparison test, or a Student t-test, all with 5\% significance was performed as appropriate, using the statistical package JMP $5.0^{\circledR}$.

\section{Results and Discussion}

\subsection{Phytochemical analysis of U. europaeus extracts}

Alkaloids were not present in the aqueous extracts, whereas all metabolites, especially tannins and saponins were detected in the methanolic extracts (Table 2).

Table 2. Phytochemical analysis of $U$. europaeus L. extracts.

\begin{tabular}{lcccc}
\hline \multicolumn{1}{c}{ Metabolite } & Alkaloid & Flavonoid & Tannin & Saponin \\
Extract & & & & \\
\hline $\mathrm{Ar}$ & $(-)$ & $(-)$ & $(+)$ & $(-)$ \\
$\mathrm{As}$ & $(-)$ & $(+)$ & $(+)$ & $(+)$ \\
$\mathrm{Mr}$ & $(-)$ & $(-)$ & $(+)$ bluish & $(+)$ \\
$\mathrm{Ms}$ & $(+)$ & $(+)$ & $(++)$ greenish & $(+)$ \\
\hline
\end{tabular}

$(-)$ : Negative result, $(+)$ : Positive result, $(++)$ : Positive result with strong evidence. $\mathrm{Ar}=$ root aqueous, $\mathrm{As}=$ shoot aqueous, $\mathrm{Mr}=$ root methanolic, $\mathrm{Ms}=$ shoot methanolic. 
The low abundance of alkaloids in the extracts may be due to the methods of extraction of the aqueous and methanolic fractions, as in the last step both involved a near neutral $\mathrm{pH}$. As alkaloids are composed of basic nitrates, they are found in plants in the form of salts of organic acids, whose solubility is far greater at lower $\mathrm{pH}$. In $U$. europaeus, the quinolizidine alkaloids $\mathrm{N}$ methylcytisine (12.2 $\left.\mathrm{mg} \mathrm{kg}^{-1} \mathrm{DM}\right)$, cytisine $(83 \mathrm{mg}$ $\mathrm{kg}^{-1} \mathrm{DM}$ ) and anagrine (32 $\mathrm{mg} \mathrm{kg}^{-1} \mathrm{DM}$ ) have been reported; these play several roles in the plant, including allelopathic interrelations (Máximo and Lourenco, 2000; Máximo et al., 2006; Hornoy et al., 2012). The genus Ulex is rich in flavonoids, particularly isoflavones and pterocarpanes (Máximo et al., 2002). Tannins are polar phenolic derivatives and are therefore soluble in water. Saponins, which are a group of oily glycosides, are soluble in methanol and water, yet were not detected in the aqueous root extracts, probably due to the fact that they are found in low concentrations.

\subsection{Evaluation of polyphenol concentration in C. annuum and L. sativa after application of $U$. europaeus extracts}

Differences were observed in the polyphenol concentration of leaf for both species cultivated in laboratory and greenhouse conditions (Figure 1). In $C$. annuum, values are significantly greater $(P<0.05)$ in greenhouse conditions after five days of application of different $U$. europaeus extracts. On the other hand, the polyphenol concentration observed in L. sativa are greater in the laboratory $(P<0.05)$. The response variable between extracts was observed only in the laboratory and for both species. In this context, the polyphenol concentration of $C$. annuum is lower in $\mathrm{C}(P<0.05$ than in the other treatments, except Ca. However, in L. sativa, the concentration in $\mathrm{Ca}$ is lower than in all other extracts, while for $\mathrm{Ar}$ it is higher $(P<0.05)$. No other significant differences are present between the rest of extracts, including the control.
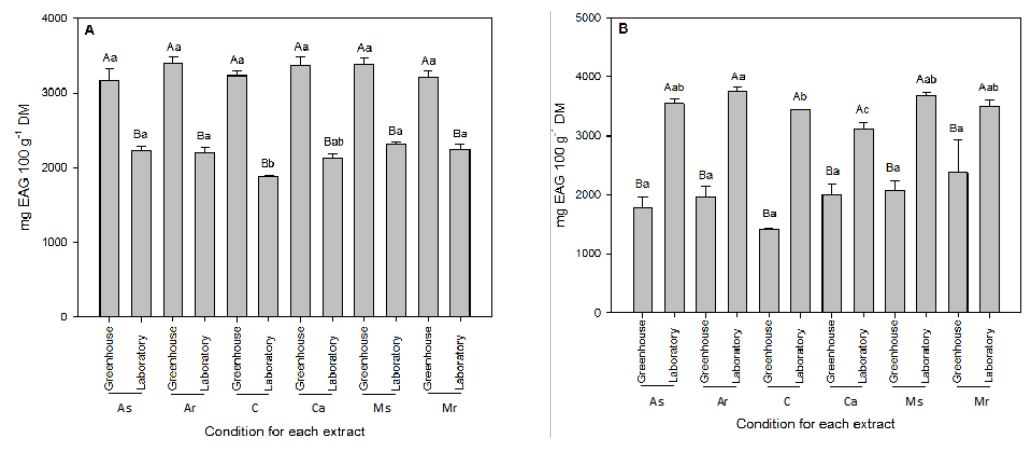

Figure 1. Polyphenol concentration obtained five days after application of methanolic and aqueous extracts of $U$. europaeus obtained from different organs. A) C. annuum leaf, B) L. sativa leaf. Different uppercase letters between bars of different environmental conditions and equal extracts, represent significant differences according to the Student t-test $(P<0.05)$. Different lowercase letters between bars of equal environmental conditions and different extracts, represent significant differences according to the Tukey test $(P<0.05)$. 
The exposure of plants to controlled (laboratory) and less controlled (greenhouse) conditions with the same treatments typically triggers greater total polyphenol levels in the greenhouse, given fluctuations in temperature, humidity, and other factors of stress (Koyama et al., 2012). However, this behaviour is only observed in C. annuum. In this sense, Divi et al. (2010) in a study with Arabidopsis, assert that tolerance to thermal stress is related to the presence of brassinosteroids which, together with other phytohormones, generate a particular response in different genotypes. In this part of the analysis, the origin (root or shoot) and nature (aqueous or methanolic) of the U. europaeus extracts did not constitute a differentiating factor in either of the two growth conditions. However, upon analysing the levels by condition (laboratory or greenhouse), they do indeed differ and behave as expected according to previous studies (Figures 2 and 3).

In laboratory-grown C. annuиm (Figure 2), the total polyphenol concentration increases concomitant with the dose, except at the highest concentration, where plants suffer a decrease in polyphenols. Regression to extract values are highly significant $(P<0.001)$, but with greater representativeness in $\mathrm{Ar}$ and $\mathrm{Ca}$.

Other than detecting higher polyphenol content in the greenhouse, with respect to those found in the laboratory, it is not possible to identify a clear trend for the variable in these less controlled conditions; indeed, the regressions are not significant $(\mathrm{P}>0.05)$. In both cases, the observed $\mathrm{C}$ values correspond to the lowest in every condition, suggesting an overall positive effect of extracts and doses on the C. annuum.

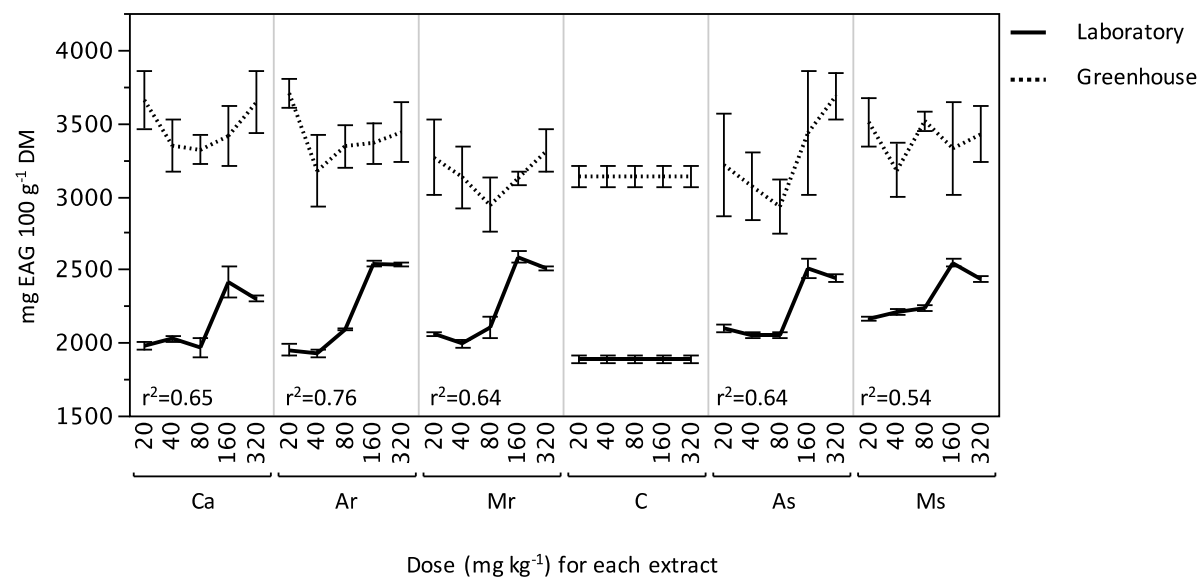

Figure 2. Polyphenol concentration of $C$. annuum after application of methanolic and aqueous extracts of $U$. europaeus obtained from different organs, under laboratory and greenhouse conditions. $\mathrm{r}^{2}=$ linear regression analysis. 
The total polyphenol concentration in C. annuum can be explained, in part, by the absence or reduction of other abiotic stress factors in controlled laboratory conditions, except in the higher doses. Such doses may cause toxicity and be generally detrimental to the physiological state of the species, as corroborated partly by Batish et al. (2008) and Medeiros et al. (2009). Additionally, the stimulation of secondary metabolism by low doses of stress-causing agents also affects primary metabolism, as explained by Cedergreen (2008) in a study on biomass production. Mitchell and Chassy (2009) point out that stress may be less attractive in production, but the nutritional value per gram of product may be superior by increasing the content of certain metabolites that improve the plant's nutritional quality.

In L. sativa (Figure 3), the total polyphenol content in laboratory conditions presents a trend similar to that found in C. annum, due to the direct relationship with increased dose, except at the highest dose. Despite the significance of the linear regression $(P<0.05)$, the representativeness is low, except in $\mathrm{Ca}$. However, in the greenhouse, no clear trend was seen in relation to the dosage (similar to C. annuum), with no significant regressions ( $P>0.05$ ).

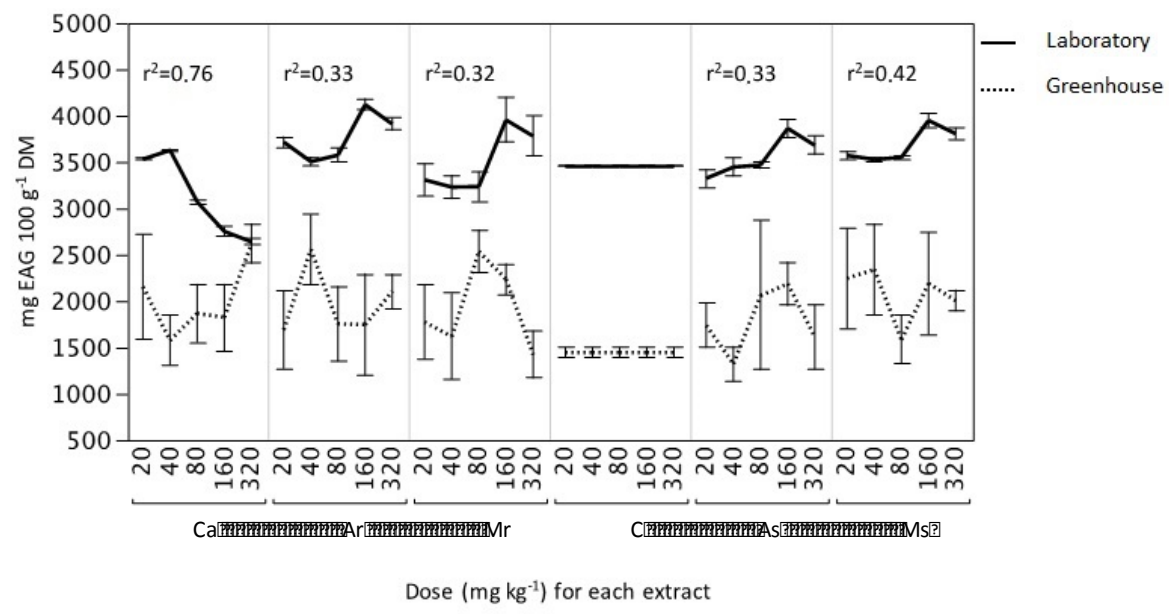

Figure 3. Polyphenol concentration of L. sativa after application of methanolic and aqueous extracts of U. europaeus obtained from different organs, under laboratory and greenhouse conditions. $\mathrm{r}^{2}=$ linear regression analysis. 
For L. sativa, the differences in the response for each dose and extract, in laboratory and in greenhouse, are striking. This phenomenon could be caused by the differences in the average temperature in the greenhouse which could be an additional stress factor for the species, thus acting as a co-variable. The temperature average was $25^{\circ} \mathrm{C}$ for the day and $16^{\circ} \mathrm{C}$ for the night in test period, with a $9^{\circ} \mathrm{C}$ of thermal amplitude. At respect, Ancillotti et al. (2015) point out that heat shock in Nicotiana langsdorffii Weinmann alter the secondary metabolism tending to raise the polyphenol concentration. In this sense, Helyes et al. (2015) found that polyphenol content rise in Solanum melongena under heat stress. Similar observations by Chua et al., (2015) in Premna serratifolia L. confirm that polyphenol concentration in harvest early is lower than later in the same day; the authors affirm that the temperature had a significant effect. On this matter, Rao and Ravishankar (2002) and Divi et al. (2010) point out that temperature is indeed a factor which, under certain conditions, could increase secondary metabolites, although the response is heavily dependent on the species. Also, it is necessary to differentiate environment temperature than soil temperature, in the last case Xue et al. (2018) found more biomass in Alpine meadow higher temperatures, of what can be inferred the absence of stress; that is, greater primary than secondary metabolism and its metabolites. The above is not applicable to $\mathrm{Ca}$ in the laboratory, given that a decreasing response is observed as the dose increases. In this case, Ca presents the expected trend when a plant is subjected to high concentrations of phytotoxic agents (that go beyond stress), with a slight stimulation in low doses and a reduction in the polyphenol concentration in higher doses, acting as an elicitor (Rao and Ravishankar, 2002).

\section{Conclusions}

In summary, doses of different $U$. europaeus L. extracts, as well as environmental conditions, affect total polyphenol content when applied to both C. annuum L. and L. sativa L. In general, at increasing doses of extracts, the content of these secondary metabolites also rises. This effect is clear for both species in controlled conditions, yet more variable in the presence of other stress factors - such as temperature - in less controlled (greenhouse) conditions. These results are the first known report of a relationship between the dose of the extracts of $U$. europaeus and the induction of polyphenolic compounds. From this work, future research could focus on the characterization and identification of the specific phytochemical compounds that are beneficial for human health, thus opening up the possibility of cultivating species with high antioxidant concentration using natural products.

\section{Acknowledgements}

This work was funded by the CONICYT-PCHA/ Doctorado Nacional/2016-21160984 scholarship. We thank Michael Handford (Universidad de Chile) for language support.

\section{References}

Ancillotti, C., Bogani, P., Biricolti, S., Calistri, E., Checchini, L., Ciofi, L., Gonnelli, C., Del Bubba, M. 2015. Changes in polyphenol and sugar concentrations in wild type and genetically modified Nicotiana langsdorffii Weinmann in response to water and heat stress. Plant Physiology and Biochemistry. 97: 52-61. 
Alghazeer, R., El-Saltani, H., Saleh, N., Al-Najjar, A., Hebail, F. 2012. Antioxidant and antimicrobial properties of five medicinal Libyan plants extracts. Natural Science. 4: 324-335.

Andarwulan, N., Kurniasih, D., Apriady, R., Rahmat, H., Roto, A., Bolling, B. 2012. Polyphenols, carotenoids, and ascorbic acid in underutilized medicinal vegetables. Journal of Functional Foods. 4: 339-347.

Araujo, I., Peruch, L., Stadnik, M. 2012. Efeito do extrato de alga e da argila silicatada na severidade da alternariose e na produtividade da cebolinha comum (Allium fistulosum L.). Tropical Plant Pathology. 37: 363-367.

Batish, D., Singh, H., Kaur, M., Kohli, R., Yadav, S. 2008. Caffeine affects adventitious rooting and causes biochemical changes in the hypocotyl cuttings of mung bean (Phaseolus aureus Roxb.). Acta Physiologiae Plantarum. 30: 401-405.

Batlang, U. 2008. Benzyladenine plus gibberellins (GA4+7) increase fruit size and yield in greenhouse-grown hot pepper (Capsicum annuum L.). Journal of Biological Sciences. 8: 659-662.

Benayad, N., Mennane, R., Charof, R., Hakiki, A., Mosaddak, M. 2013. Antibacterial activity of essential oil and some extracts of Cistus ladaniferus from Oulmes in Morocco. Journal of Materials and Environmental Sciences. 4: 1066-1071.

Bourgaud, F., Gravot, A., Milesi, S., Gontier, E. 2001. Production of plant secondary metabolites: a historical perspective. Plant Science. 161: 839-851.

Cedergreen, N. 2008. Herbicides can stimulate plant growth. Weed Research. 48: 429-438.

Cheng, D., Pogrebnyak, N., Kuhn, P., Krueger, C., Johnson, W., Raskin, I. 2014. Development and phytochemical characterization of high polyphenol red lettuce with anti-diabetic properties. PloS one. 9: e91571.
Chua, I.Y., King, P.J., Ong, K.H., Sarbini, S.R., Yiu, P.H. 2015. Influence of light intensity and temperature on antioxidant activity in Premna serratifolia L. Journal of Soil Science and Plant Nutrition. 15: 605-614.

Costa, R., Magalhães, A., Pereira, J., Andrade, P., Valentão, P., Carvalho, M., Silva, B. 2009. Evaluation of free radical-scavenging and antihemolytic activities of quince (Cydonia oblonga) leaf: a comparative study with green tea (Camellia sinensis). Food Chemical Toxicology. 47: 860-865.

Divi, U., Rahman, T., Krishna, P. 2010. Brassinosteroid-mediated stress tolerance in Arabidopsis shows interactions with abscisic acid, ethylene and salicylic acid pathways. BMC Plant Biology. 10: 1 .

Dixon, R., Paiva, N. 1995. Stress-induced phenylpropanoid metabolism. Plant Cell. 7: 1085-1097.

García-Tirado, J., Rieger-Reyes, C., Saz-Peiró, P. 2012. Effect of flavonoids in the prevention of lung cancer: systematic review. Medicina Clínica. 139: 358-363.

Georgé, S., Brat P., Alter P., Amiot, M. 2005. Rapid determination of polyphenols and vitamin $\mathrm{C}$ in plant-derived products. Journal of Agricultural and Food Chemistry. 53: 1370-1373.

Helyes, L., Nagy, Z., Daood, H., Pék, Z., Lugasi, A. 2015. The simultaneous effect of heat stress and water supply on total polyphenol content of eggplant. Applied Ecology and Environmental Research. 13: 583-595.

Hornoy, B., Atlan A., Tarayre, M., Dugravot, S., Wink, M. 2012. Alkaloid concentration of the invasive plant species Ulex europaeus in relation to geographic origin and herbivory. Naturwissenschaften. 99: 883-892.

Ioslovich, I. 2009. Optimal control strategy for greenhouse lettuce: incorporating supplemental lighting. Biosystems Engineering. 103: 57-67. 
Karthishwaran, K., Mirunalini, S., Dhamodharan, G., Krishnaveni, M., Arulmozhi, V. 2010. Phytochemical investigation of methanolic extracts of the leaves of Pergularia daemia. Journal of Biological Sciences. 10: 242-246.

Kaufman, S., Kaufman, W. 2013. Invasive plants: a guide to identification, impacts, and control of common North American species. $2^{\circ}$ edition. Stackpole Books. Mechanicsburg, USA, 530 p.

Kolewe, M., Gaurav, V., Roberts, S. 2008. Pharmaceutically active natural product synthesis and supply via plant cell culture technology. Molecular Pharmaceutics 5, 243-256.

Koyama, R., Itoh, H., Kimura, S., Morioka, A., Uno, Y. 2012. Augmentation of antioxidant constituents by drought stress to roots in leafy vegetables. HortTechnology. 22: 121-125.

Korkutata, N., Kavaz, A. 2015. A comparative study of ascorbic acid and capsaicinoid contents in red hot peppers (Capsicum annuum L.) grown in southeastern Anatolia region. International Journal of Food Properties. 18: 725-734.

Martini, D., Del Bo, C., Porrini, M., Ciappellano, S., Riso, P. 2017. Role of polyphenols and polyphenol-rich foods in the modulation of PON1 activity and expression. The Journal of Nutritional Biochemistry. 48: 1-8.

Matthei, O., Marticorena, C., Quezada, M., Rodríguez, R. 1995. Manual de las malezas que crecen en Chile. Alfabeta Impresores. Santiago, Chile, $545 \mathrm{p}$.

Máximo, P., Lourenco, A. 2000. New quinolizidine alkaloids from Ulex jussiaei. Journal of Natural Products. 2: 201-204.

Máximo, P., Lourenco, A., Savluchinske, S., Roseiro, J. 2002. Flavonoids from Ulex airensis and Ulex europaeus ssp. europaeus. Journal of Natural Products. 65: 175-178.
Máximo, P., Lourenço, A., Tei, A., Wink, M. 2006. Chemotaxonomy of Portuguese Ulex: quinolizidine alkaloids as taxonomical markers. Phytochemistry. 67: 1943-1949.

Medeiros, F., Resende, M., Medeiros, F., Zhang, H., Paré, P. 2009. Defense gene expression induced by a coffee-leaf extract formulation in tomato. Physiological and Molecular Plant Pathology. 74: 175-183.

Mitchell, A., Chassy, A. 2009. Antioxidants and the nutritional quality of organic agriculture. In: Annual meeting of the American Advancement of Science, Chicago, USA, 12-16 pp.

Ortiz de Elgueta-Culebras, G., Sánchez-Vioque, R., Berruga, M. I., Herraiz-Peñalver, D., SantanaMéridas, O. 2017. Antifeedant effects of common terpenes from Mediterranean aromatic plants on Leptinotarsa decemlineata. Journal of Soil Science and Plant Nutrition. DOI: 10.4067/S071895162017005000034

Pascual, M., Carretero, M., Slowing, K., Villar, A. 2002. Simplified screening by TLC of plant drugs. Pharmaceutical Biology. 40: 139-143.

Ramirez-Estrada, K., Vidal-Limon, H., Hidalgo, D., Moyano, E., Golenioswki, M., Cusidó, R.M., Palazon, J. 2016. Elicitation, an effective strategy for the biotechnological production of bioactive high-added value compounds in plant cell factories. Molecules. 21: 182.

Rao, S., Ravishankar, G. 2002. Plant Cell cultures: Chemical factories of secondary metabolites. Biotechnology Advances. 20: 101-153.

Sayin, K., Arslan, D. 2015. Antioxidant Properties, Ascorbic Acid and Total Carotenoids Values of Sweet and Hot Red Pepper Paste: A Traditional Food in Turkish Diet. World Academy of Science, Engineering and Technology. International Journal of Biological, Biomolecular, Agricultural, 
Food and Biotechnological Engineering. 9: 829832.

Tighe, R., Montalba, R., Leonelli, G., Contreras, A. 2014. Efecto de dos extractos botánicos en el desarrollo y contenido de polifenoles de ají (Capsicum annum L.). Revista Mexicana de Ciencias Agrícolas. 5: 115-127.

Tighe-Neira, R., Díaz-Harris, R., Leonelli-Cantergiani, G., Iglesias-González, C., Martínez-Gutiérrez, M., Morales-Ulloa, D., Mejías-Lagos, P. 2016. Efecto de extractos de Ulex europaeus L. en la producción de biomasa de plántulas de ají (Capsicum annuиm L.), en condiciones de laboratorio. Idesia (Arica). 34: 19-25.

Tighe-Neira, R., Alberdi, M., Arce-Johnson, P., Romero-Romero, J. L., Reyes-Díaz, M., Inostroza-Blancheteau, C. 2017. Foods with functional properties and their potential uses in human health. In Superfood and Functional Food-An Overview of Their Processing and Utilization. InTech $185-219$ pp.
Upadhyay, B., Singh, K., Kumar, A. 2010. Ethno-Medicinal, Phytochemical and Antimicrobial Studies of Euphorbia tirucalli L. Journal of Phytology 2: 65-77.

Xue, R., Yang, Q., Miao, F., Wang, X., Shen, Y. 2018. Slope aspect influences plant biomass, soil properties and microbial composition in alpine meadow on the Qinghai-Tibetan plateau. Journal of Soil Science and Plant Nutrition. DOI: 10.4067/ S0718-95162018005000101.

Zhong, J. 2011. Plant Secondary Metabolites. In: Moo-Young M. (Eds.) Comprehensive Biotechnology Academic Press. Burlington, USA, 299308 pp. 